\title{
Postmortem Analysis of Injuries by Roadkill of a White-eared Opossum (Didelphis Albiventis) by Radiographs and Forensic Necropsy-A Virtopsy Case Report
}

\author{
Laila Massad Ribas ${ }^{1,2^{*}}$, Mara Rita Rodrigues Massad ${ }^{1}$, Tália Missen Tremori ${ }^{1}$, Sérvio Túlio Jacinto Reis ${ }^{1}$, Talita Eising ${ }^{1}$ and Noeme Sousa Rocha \\ ${ }^{1}$ Faculdade de Medicina Veterinária e Zootecnia da Universidade Estadual Paulista, Júlio de Mesquita Filho, campus Botucatu \\ ${ }^{2}$ Rua Prof. Fernando de Azevedo, 50-São Paulo-SP, Brazil.
}

*Corresponding author: Laila Massad Ribas, Rua Prof. Fernando de Azevedo, 50-São Paulo-SP, Brazil, Tel: 55-11-3719-5811; E-mail: lailamassad@gmail.com

Rec date: Nov 30, 2015; Acc date: Dec 17, 2015; Pub date: Dec 19, 2015

Copyright: $\odot 2015$ Ribas LM, et al. This is an open-access article distributed under the terms of the Creative Commons Attribution License, which permits unrestricted use, distribution, and reproduction in any medium, provided the original author and source are credited.

\begin{abstract}
The white-eared opossum (Didelphis albiventris) is one of the most road-killed animals in Brazil, especially due to its opportunistic habits and great adaptation to urban environment. Although radiology is present in the veterinary daily routine, it is uncommon in forensic necropsies, especially in wild animals. A white-eared opossum killed by a vehicle in a road of the State of São Paulo, Brazil was submitted to entire-body radiographs followed by forensic necropsy. The images revealed diffuse increased radio-opacity in both hemi-thoraces possibly of hemorrhagic origin, whereas the forensic necropsy findings were consistent with bloody pleural effusion. It was possible to conclude that postmortem radiographs in wild animals could contribute to determine the cause of death and improve forensic investigations.
\end{abstract}

Keywords: Forensic science; Forensic pathology; Postmortem diagnosis; Veterinary radiology; Animals; Wildlife

\section{Introduction}

The expansion of the road network has a direct impact on wildlife, especially on mammals due to alteration, degradation, conversion, and loss of their habitats [1-4]. The Brazilian Center for Studies on Road Ecology estimates that 475 million wild animals are killed on roads annually in Brazil [5]. The white-eared opossum (Didelphis albiventris) is one of the main species killed by motor vehicles when searching for food, especially pregnant or lactating females, the main cause of road crossing by this species [5,6]. Besides being an animal tolerant and with opportunistic habits, the opossum has great adaptation to the urban environment, making it an easy victim of roadkill $[7,8]$.

When a wild animal is killed a carefully documentation of the case is the most important part of the investigation and it can be made by photographic records, correct identification of the species involved, a site visit and proper collection, transportation, storage and submission of evidence [9].

In human forensic medicine, one of the main resources to identify individuals is radiographic images, especially when the body is skeletonized [10]. Before the forensic necropsy, an entire-body radiograph simplifies the examination [11] and provides important additional information regarding the extent and chronicity of extremity trauma that may not be documented at autopsy [12].

Although x-rays have been present in forensic medicine since 1896 $[13,14]$, it was only in 2003 that researchers at the University of Bern, Switzerland, joined conventional radiography with modern imaging methods such as computed tomography, nuclear magnetic resonance and photogrammetry to perform minimally invasive autopsies of the entire-body. They created the portmanteau Virtopsy (virtual and autopsy), which has been increasingly used to merge Forensic Radiology and Pathology $[15,16]$.

In veterinary medicine routine, Radiology is increasingly present. However, the number of this examination is still scarce in necropsy studies, even less in wild animals [17-20].

Radiographic study of animals killed by vehicles could contribute not only to the cause of death but as an assisting research about the impact of these deaths in the Brazilian fauna. Thus a radiographic study followed by forensic necropsy was performed in a white-eared opossum (Didelphis albiventris) killed by a motor vehicle in the State of São Paulo, Brazil.

\section{Material and Methods}

A young female white-eared opossum (Didelphis albiventris) was collected on the highway SP-209 by the Environmental Military Police of São Paulo (Figure 1). The animal was sent to the campus of Botucatu of the School of Veterinary Medicine of UNESP (Universidade Estadual Paulista "Julio de Mesquita Filho") where an entire-body right lateral and ventrodorsal radiographs were performed in a GE $\mathrm{x}$-ray equipment $(150 \mathrm{kV}, 200 \mathrm{~mA} / 6.4 \mathrm{mAs})$. A veterinary radiologist analyzed the images. After the radiographic exam, a forensic necropsy was conducted by veterinary pathologist by modify Gohn method, were organs are removed by function.

\section{Results}

\section{Radiographic images}

Figure 2 shows the entire-body right lateral radiograph and Figure 3 shows ventrolateral radiographs. It was possible to conclude that the cause of death was an accumulation of fluids in the thorax, possibly of hemorrhagic origin due to the history of trauma. 
Citation: Ribas LM, Massad MRR, Tremori TM, Reis STJ, Eising T, et al. (2016) Postmortem Analysis of Injuries by Roadkill of a White-eared Opossum (Didelphis Albiventis) by Radiographs and Forensic Necropsy-A Virtopsy Case Report. J Veterinar Sci Technol 7: 282. doi: $10.4172 / 2157-7579.1000282$

Page 2 of 4

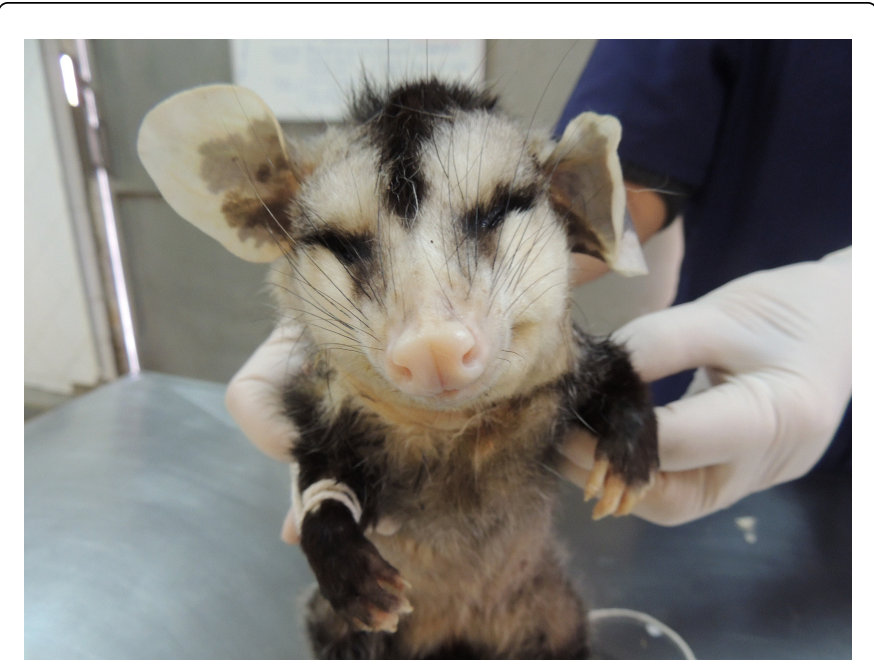

Figure 1: White-eared opossum (Didelphis albiventris).

\section{Forensic necropsy}

The external examination of the body revealed no degree of dehydration, slightly pale mucosa, blood in the perianal region, hematoma in the inguinal region and medial region of the left hind limb.

The in situ examination revealed bloody effusion in pleural cavity and no anatomical abnormalities in the abdominal cavity (Figure 4).

Internal examination of thorax revealed bloody effusion, but pericardium, heart and lungs were normal.

Internal examination of the abdomen revealed a fatty liver with increased volume, hemoglubinuric impregnation on the wall of the organs, bowels containing hard stools and lots of perirenal fat. Besides this, there was presence of hematoma in the buttock and spine area.

The cause of death was cardiac arrest and the main alteration was hemorrhagic pleural effusion.

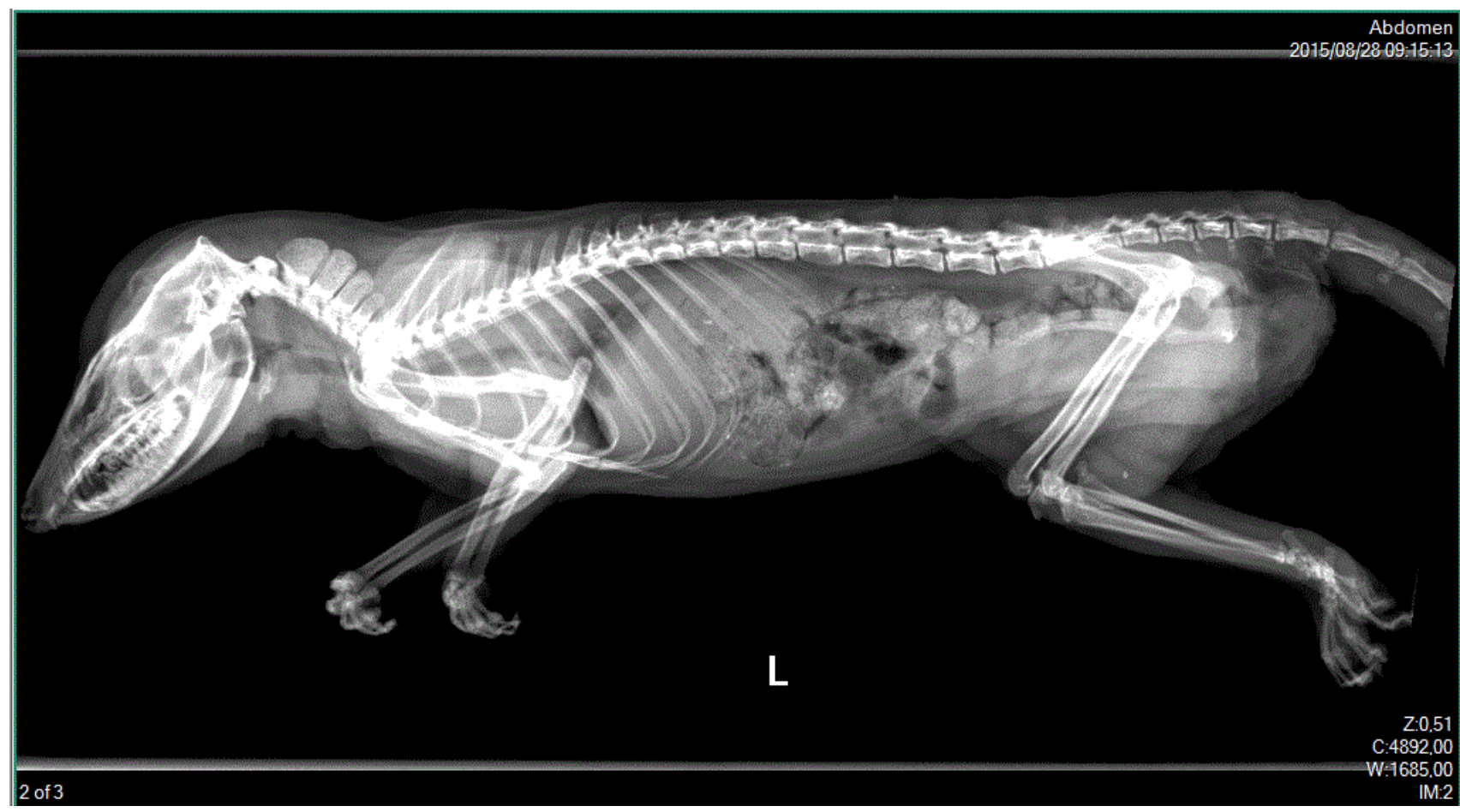

Figure 2: Entire-body right lateral radiograph. The image reveals diffuse increased radio-opacity in the thorax, which did not allow visualization of the cardiac silhouette or tracheal path. The abdomen was normal and there were no evidence of fractures or luxation.

\section{Discussion}

We evaluated postmortem injuries by radiologic examination and forensic necropsy, caused by roadkill of a white-ear opossum in a road of the State of São Paulo, Brazil. The images revealed evidences founded in the forensic necropsy. The pleural effusion revealed by the radiographs was consistent with bloody effusion due to the history of trauma and, the forensic necropsy confirmed this evidence, suggesting that clinical history, images and necropsy are better tools if they work together.

Although the use of radiologic images in human forensic cases have started soon after the discovery of the x-rays by Wilhelm Conrad Röntgen in 1985 [13], in Forensic Veterinary Medicine this practice is still not part of the daily routine [21-23]. In addition, the amount of researches about wildlife forensic science and, publications about radiological study in this area are very scarce [17-20]. 
Citation: Ribas LM, Massad MRR, Tremori TM, Reis STJ, Eising T, et al. (2016) Postmortem Analysis of Injuries by Roadkill of a White-eared Opossum (Didelphis Albiventis) by Radiographs and Forensic Necropsy-A Virtopsy Case Report. J Veterinar Sci Technol 7: 282. doi: $10.4172 / 2157-7579.1000282$

Page 3 of 4

In humans, Forensic Radiology is a very important tool to identify individuals when fingerprint, DNA and odontological comparisons are not possible [24]. Conventional $\mathrm{x}$-rays is the cheapest radiological exam and could contribute to forensic investigation in wild animal crimes and/or violent death, especially the invisibility of hidden fractures, identification of pneumothorax and air embolism, which, therefore, add especial information to forensic necropsy $[23,25]$.

The Red List Category \& Criteria, which classify the animals according to the risk of extinction, considers the white-ear opossum a "least concern" animal, because of its wide distribution and its tolerance in habitat modification [26]. However, it is very important to register any kind of accident, violence or crime against a wild animal, especially in one of the most road-killed species.

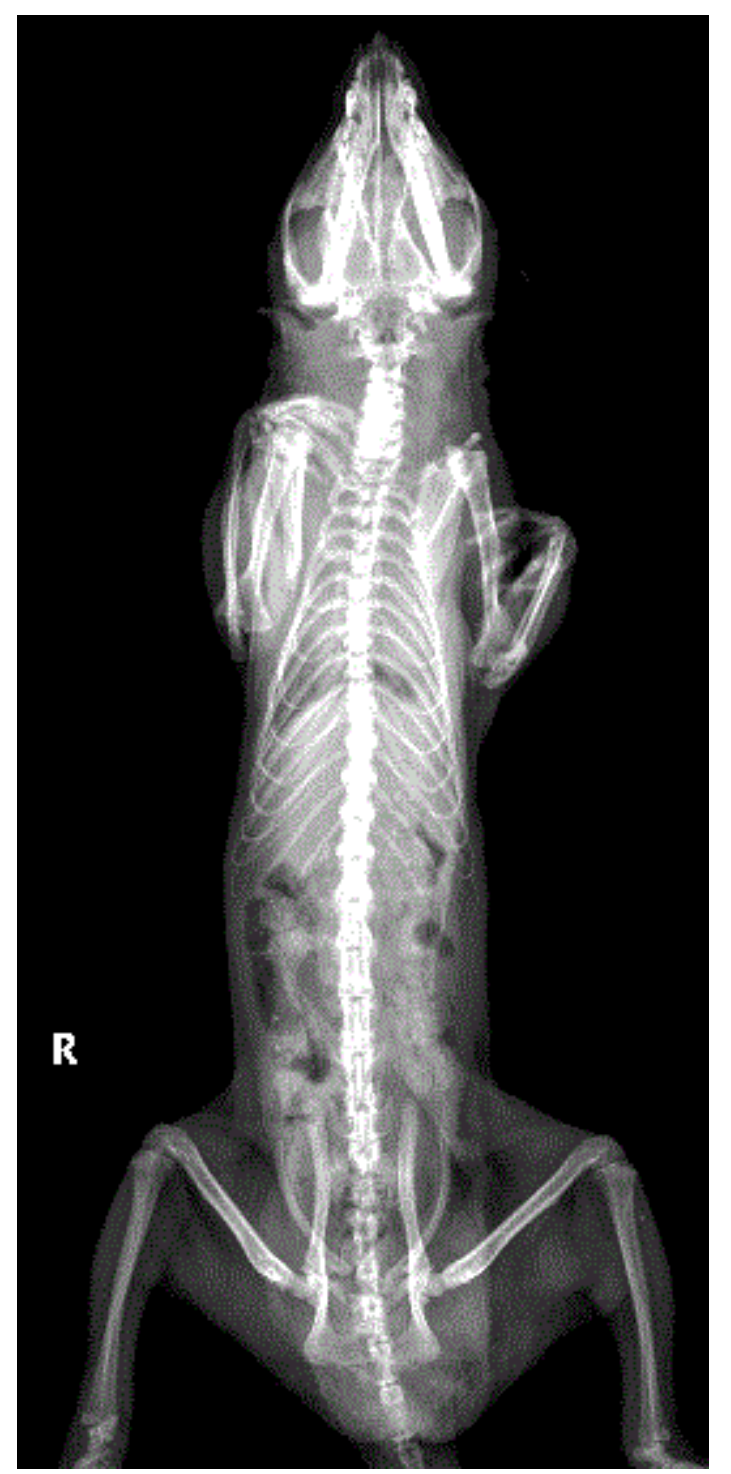

Figure 3: Entire-body ventrodorsal radiograph. The image reveals diffuse increased radio-opacity in both hemi-thoraces, which did not allow visualization of the cardiac silhouette. The abdomen was normal and there were no evidence of fractures or luxation.

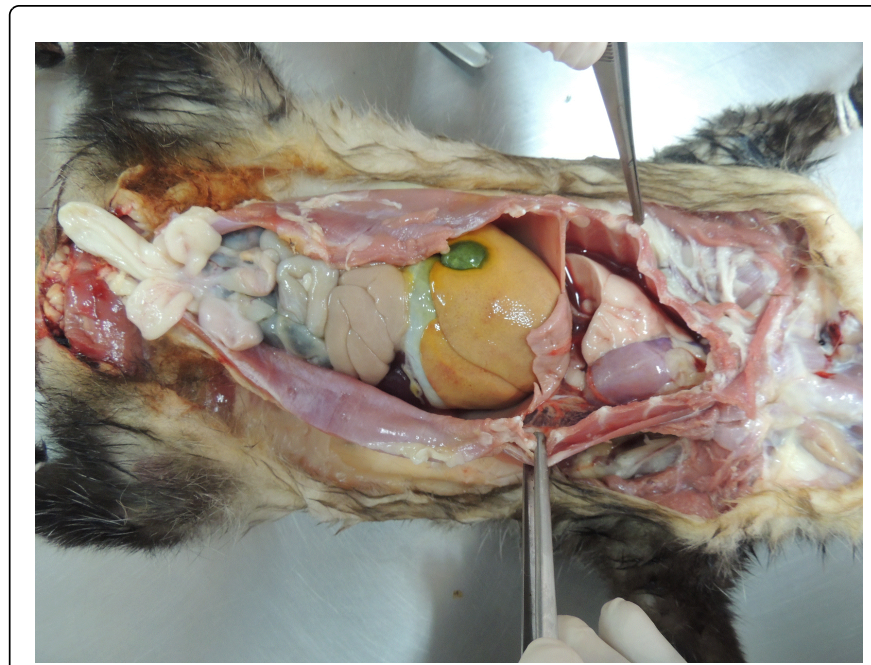

Figure 4: In situ necropsy findings. In situ necropsy revealed bloody effusion in thorax cavity.

\section{Conclusion}

Forensic radiology, or Virtopsy, is a key technique that is already part of (and sometimes a substitute of) forensic postmortem examination in humans [27]. In Forensic Veterinary Medicine, however, is a science in its infancy. In this work we demonstrate that the radiologic examination revealed aspects that complement the regular necropsy, helping forensic doctors to identity the causes of death. This is particularly important in determining the cases of violent deaths, either of criminal or other violent origins.

\section{Acknowledgments}

We thank Professor Eduardo Massad for his enormous intellectual contribution. This work was supported by CAPES (Coordenação de Aperfeiçoamento de Pessoal de Nível Superior).

\section{References}

1. Klippel AH, Oliveira PV, Britto KB, Freire BF, Moreno MR, et al. (2015) Using DNA barcodes to identify road-killed animals in two atlantic forest nature reserves, Brazil. PLoS One 10: e0134877.

2. Ascensão F, Grilo C, LaPoint S, Tracey J, Clevenger AP, et al. (2014) Interindividual variability of stone marten behavioral responses to a highway. PLoS One 9: e103544.

3. Jackson ND, Fahrig L (2011) Relative effects of road mortality and decreased connectivity on population genetic diversity. Biological Conservation 144: 3143-3148.

4. CBEE (2015) Brazilian Center for Studies on Road Ecology (2015).

5. Meneguetti DUO, Meneguetti PSB, Trevisan The (2010) Geo-referencing and re-evaluation of mortality from trampling of wild animals on the line 200 between the municipalities of the West Ouropreto and RO-Paradise Valley. Scientific Journal of the Faculty of Education and Environment 1: 58-64.

6. Hegel CGZ, Consalter GC, Zanella N (2012) Wild Mammals run over the RS -135 highway, north of the Rio Grande do Sul State. Magazine Biotemas 25: 165-170.

7. Prado HM, Murrieta RS, Adams C, Brondizio ES (2014) Local and scientific knowledge for assessing the use of fallows and mature forest by 
Citation: Ribas LM, Massad MRR, Tremori TM, Reis STJ, Eising T, et al. (2016) Postmortem Analysis of Injuries by Roadkill of a White-eared Opossum (Didelphis Albiventis) by Radiographs and Forensic Necropsy-A Virtopsy Case Report. J Veterinar Sci Technol 7: 282. doi: $10.4172 / 2157-7579.1000282$

Page 4 of 4

large mammals in SE Brazil: identifying singularities in folkecology. J Ethnobiol Ethnomed 10: 7.

8. Buchheister A, Latour RJ (2015) Diets and trophic-guild structure of a diverse fish assemblage in Chesapeake Bay, USA. Journal of Fish Biology 86: 967-992.

9. Cooper JE, Cooper ME (2007) Introduction to veterinary and comparative forensic medicine. Blackwell, Oxford.

10. Miziara ID (2014) Practical Handbook of Forensic Medicine. Atheneu, São Paulo.

11. Munro R (1998) Forensic necropsy. Seminars in Avian and Exotic Pet Medicine 4: 201-209.

12. McGraw EP, Pless JE, Pennington DJ, White SJ (2002) Postmortem radiography after unexpected death in neonates, infants, and children: should imaging be routine? AJR Am J Roentgenol 178: 1517-21.

13. Brogdon BG, Lichtenstein JE (2011) Forensic radiology in historical perspective. In: Thali, ML, Viner, MD, Brogdon BG (Eds) Brogdon's forensic radiology (2ndedn) CRC Press, Boca Raton.

14. Cox J, Kirkpatrick RC (1896) The new photography, with report of a case in which a bullet was photographed in the leg. Montreal Medical Journal.

15. Thali MJ, Yen K, Schweitzer W, Vock P, Boesch C, et al. (2003) Virtopsy a new imaging horizon in forensic pathology邓: virtual autopsy by postmortem multislice computed tomography (MSCT) and magnetic resonance imaging (MRI)-a feasibility study. Journal of Forensic Sciences 48: 386-403.

16. Virtopsy trademark (2015).

17. Cooper ME (1998) Birds, exotic animals, and the law. Seminars in Avian and Exotic Pet Medicine 7: 166-175.
18. Stroud RK (1998) Wildlife forensics and the veterinary practitioner. Seminars in Avian and Exotic Pet Medicine 7: 182-192.

19. Thali MJ, Kneubuehl BP, Bolliger SA, Christe A, Koenigsdorfer U, et al. (2007) Forensic veterinary radiology: ballistic-radiological 3D computertomographic reconstruction of an illegal lynx shooting in Switzerland. Forensic Sci Int 171: 63-66.

20. Yang SH, Huang XM, Xia R, Xu YC, Dahmer TD (2011) Use of femur bone density to segregate wild from farmed Dybowski's frog (Rana dybowskii). Forensic Sci Int 207: 61-65.

21. Heng HG, Teoh WT, Sheikh-Omar AR (2008) Postmortem abdominal radiographic findings in feline cadavers. Vet Radiol Ultrasound 49: 26-29.

22. Heng HG, Selvarajah GT, Lim HT, Ong JS, Lim J, et al. (2009) Serial postmortem thoracic radiographic findings in canine cadavers. Forensic Sci Int 188: 119-124.

23. Heng HG, Selvarajah GT, Lim HT, Ong JS, Lim J, et al. (2009) Serial postmortem abdominal radiographic findings in canine cadavers. Forensic Sci Int 192: 43-47.

24. Quatrehomme G, Biglia E, Padovani B, du Jardin P, Alunni V (2014) Positive identification by X-rays bone trabeculae comparison. Forensic Sci Int 245C: e11-e14.

25. McPherson JJ, Feigin DS, Bellamy RF (2006) Prevalence of tension pneumothorax in fatally wounded combat casualties. J Trauma 60:573-578.

26. Red List (2015).

27. Panda A, Kumar A, Gamanagatti S, Mishra B (2015) Virtopsy computed tomography in trauma: normal postmortem changes and pathologic spectrum of findings. Curr Probl Diagn Radiol 44:391-406. 